\title{
Meta-analysis of the benefit of hypomethylating agents before allogeneic hematopoietic stem cell transplantation in myelodysplastic syndromes
}

\author{
Liu Liu ${ }^{1}$ (1) $\cdot$ Menglu Jia ${ }^{1} \cdot$ Ling Sun $^{1} \cdot$ Wenliang Tian $^{1} \cdot$ Ping Tang $^{1} \cdot$ Zhongxing Jiang $^{1}$
}

Received: 24 January 2021 / Accepted: 7 April 2021 / Published online: 17 April 2021

(C) The Author(s) 2021

\begin{abstract}
Hypomethylating agents (HMAs) are effective therapies in myelodysplastic syndromes (MDS), but allogeneic hematopoietic stem cell transplantation (allo-HSCT) is the only way to cure MDS. According to the current literature, it is difficult to confirm whether HMAs bridging therapy is beneficial for MDS patients receiving allo-HSCT. Therefore, we tried to evaluate the effect of HMAs on long-term survival of the MDS patients. Databases, including PubMed, Embase Ovid, and the Cochrane Library, were searched for studies published up to January 10, 2021. Patients who accepted HMAs bridging to allo-HSCT were defined as experimental group, while patients who received the best supportive care (BSC) before allo-HSCT were control group. Overall survival (OS) was the primary end point. Seven studies were included in the final analysis. The final results showed no OS differences between patients accepted HMAs before allo-HSCT and those received BSC (HR $=0.86$, 95\% CI: 0.64-1.15, $p=0.32$ ), indicating that MDS patients' long-term survival did not benefit from HMAs bridging therapy before allo-HSCT. This conclusion needs to be further verified by a large number of prospective randomized controlled trials, which have guiding significance for the treatment of MDS patients.
\end{abstract}

Keywords Myelodysplastic syndromes · Hypomethylating agents · Allogeneic hematopoietic stem cell transplantation · Meta-analysis

\section{Introduction}

Myelodysplastic syndrome (MDS) is a group of heterogeneous clonal diseases originated from hematopoietic stem cells and characterized by myelodysplasia. Its clinical manifestations include anemia, infection and hemorrhage caused by hemocytopenia, and variable risk progressed to acute myeloid leukemia (AML).

Recent studies have shown that epigenetic changes, especially abnormal DNA methylation, are important factors leading to the occurrence and development of MDS [1-3]. HMAs, azacitidine (AZA) and decitabine (DEC), have been approved by FDA for MDS treatment since 2004. A number

Liu Liu, Menglu Jia: contributed equally to this work.

Liu Liu

liuliuxx1983@163.com

1 Department of Hematology, First Affiliated Hospital of Zhengzhou University, 1 Jianshe East Road, Zhengzhou 450052, China of studies have shown that HMAs are beneficial not only to improve the OS and leukemia transformation-free survival, but also reduce the infection rate and dependence of red blood cell transfusion of MDS patients [4-6]. Unfortunately, only $40 \%-50 \%$ of patients respond to HMAs treatment, and complete response rate is $10 \%-20 \%$. Among clinical responders, the majority will experience loss of response and disease progression [7-9]. So, allo-HSCT is the only way to cure MDS to date, with a OS of $25 \%-52 \%$ [10-13]. However, HSCT candidates often need to wait several months, for the appropriate donor. Disease progression may result in losing the opportunity of transplantation, so the bridging treatment before allo-HSCT is particularly important. At present, common bridging therapies include demethylation therapy, conventional chemotherapy and the BSC.

The inhibition of DNA methyltransferase by HMAs is thought to be responsible for the hypomethylation and reactivation of tumor suppressor genes, inducing the terminal differentiation and apoptosis of neoplastic cells, which may contribute to improvements in allo-HSCT outcome by a reduction in tumor burden. And demethylation before 
allo-HSCT did improve the overall survival rate in some reports [14-18]. Alternatively, an increase in phenotypic expression during the differentiation and modification of leukemia cells may make them susceptible to immune surveillance mechanisms and result in their increased sensitivity to a GVL effect of allo-HSCT[19, 20]. Though exact mechanism is not clear, it seems rational for HMAs as a bridging therapy to allo-HSCT.

It is unclear, however, whether treatment with HMAs before allo-HSCT will increase the toxicity of the conditioning regimen or otherwise affect the results of transplantation, and whether patients with certain risk factors such as old age, complex karyotype, multi-gene mutations can benefit. Therefore, the purpose of this study is to explore the longterm efficacy of HMAs before allo-HSCT by integrating the clinical research in the current environment.

\section{Materials and methods}

\section{Data sources and searches}

The plan of this study was made in advance. We reported this meta-analysis based on the preferred reporting items for systematic reviews and meta-analyses. We did a full search using several databases: PubMed, EMBASE Ovid, and Cochrane Library (from database creation to January 10, 2021). We screened the abstracts and titles of articles eligible for further review. The full text of the research has been published and reviewed. The review of this meta-analysis has not been registered with Prospero.

\section{Inclusion and exclusion}

The inclusion and exclusion criteria were as follows: (1) this study focused on the effect of HMAs on the prognosis of MDS patients before allo-HSCT; (2) in this study, bridging treatments before transplantation were HMAs and BSC; (3) sufficient clinical data were provided in this study, at least the OS; and (4) the hazard ratio (HR) and its $95 \%$ confidence interval $(95 \% \mathrm{CI})$ were directly reported, or calculated from raw data; (5) the study was published in full in English; (6) the study included human subjects; (7) the article was not a review, case report or animal study. If the same or overlapping data were presented in multiple studies, only the most important or highest quality studies were included. Differences were resolved through discussion.

\section{Data extraction and outcome measures}

Two reviewers independently extracted information from each eligible study and entered it into a spreadsheet. The data included the name of the first author, year of publication, country, time of inclusion, number of patients, age, HMAs classification, MDS subtype, MDS classification standard, bone marrow cell count, international prognostic scoring system (IPSS) score, human leukocyte antigen (HLA) matching, stem cell source and conditioning regime. We chose OS as the primary endpoint. OS was defined as the time from transplantation to the last follow-up of patients who died or survived. When HR doesn't have a report, we try to contact the author to get it, or use the method previously reported to calculate it.

\section{Methodologic quality and risk of bias}

We used the Cochrane risk bias assessment tool to assess the bias risk in the trial, including the following areas: random sequence generation, allocation concealment, blinding of participants and personnel, blinding of outcome assessment, incomplete outcome data and selective reporting and other bias. Using the Cochrane risk bias assessment tool, bias risk can be assessed as low, unknown, or high. Two reviewers independently assessed the risk of bias in each study. Any conflict was resolved by consensus.

\section{Analysis}

The calculation was carried out in stata12.0. By calculating HRs and its 95\% CI, the influence of HMAs on OS of transplant patients was evaluated by general reverse variance method. $P$ value less than 0.05 was considered statistically significant. Chi-square test was used to evaluate the heterogeneity of the study, and $P$ value less than 0.10 was significant. We use the $\mathrm{I}^{\wedge} 2$ statistic to quantify heterogeneity. When the value of $I^{\wedge} 2$ is less than $25 \%$, between 25 and $50 \%$, and more than $50 \%$, the heterogeneity is considered as low, medium and high, respectively. If high heterogeneity is detected, a random effect model is used; otherwise, a fixed effect model is used for meta-analysis. We also use subgroup analysis to analyze the source of heterogeneity. The sensitivity analysis evaluates the stability of the combined results by the sequence omission of one study at a time. Funnel plot, Beck test and egger test were used to evaluate publication bias (Figs. 1 and 2

\section{Results}

\section{Study selection}

As shown in Fig. 3 (study selection flowchart), 352 studies were searched from the database. Five articles have been added to the analysis through reference retrieval. After 68 repetitions were eliminated, 289 citations were screened for titles and abstracts, of which 254 citations 
Fig. 1 Risk of research bias

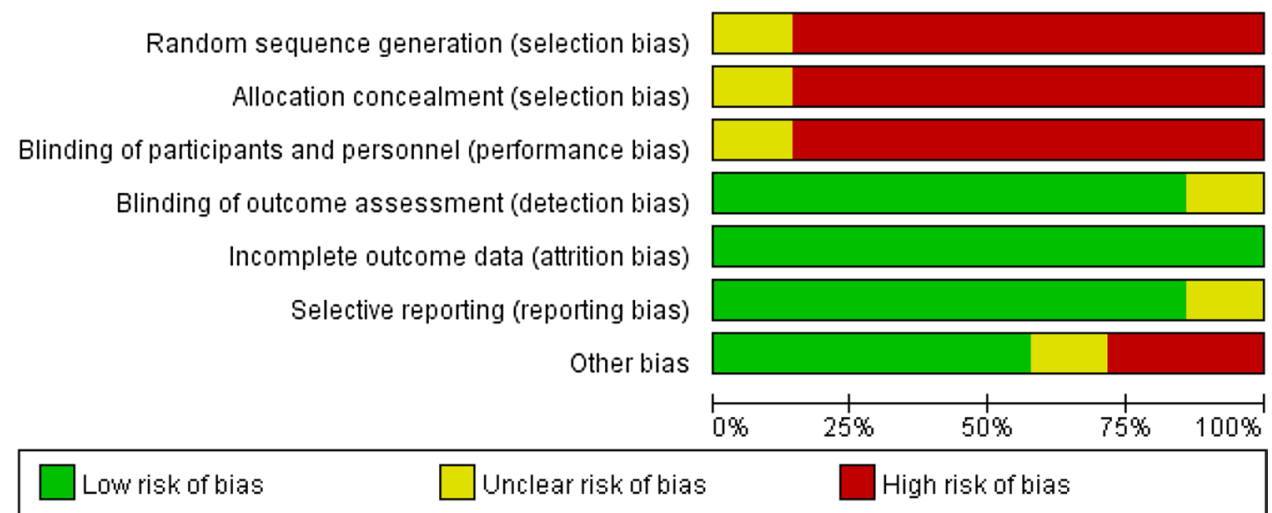

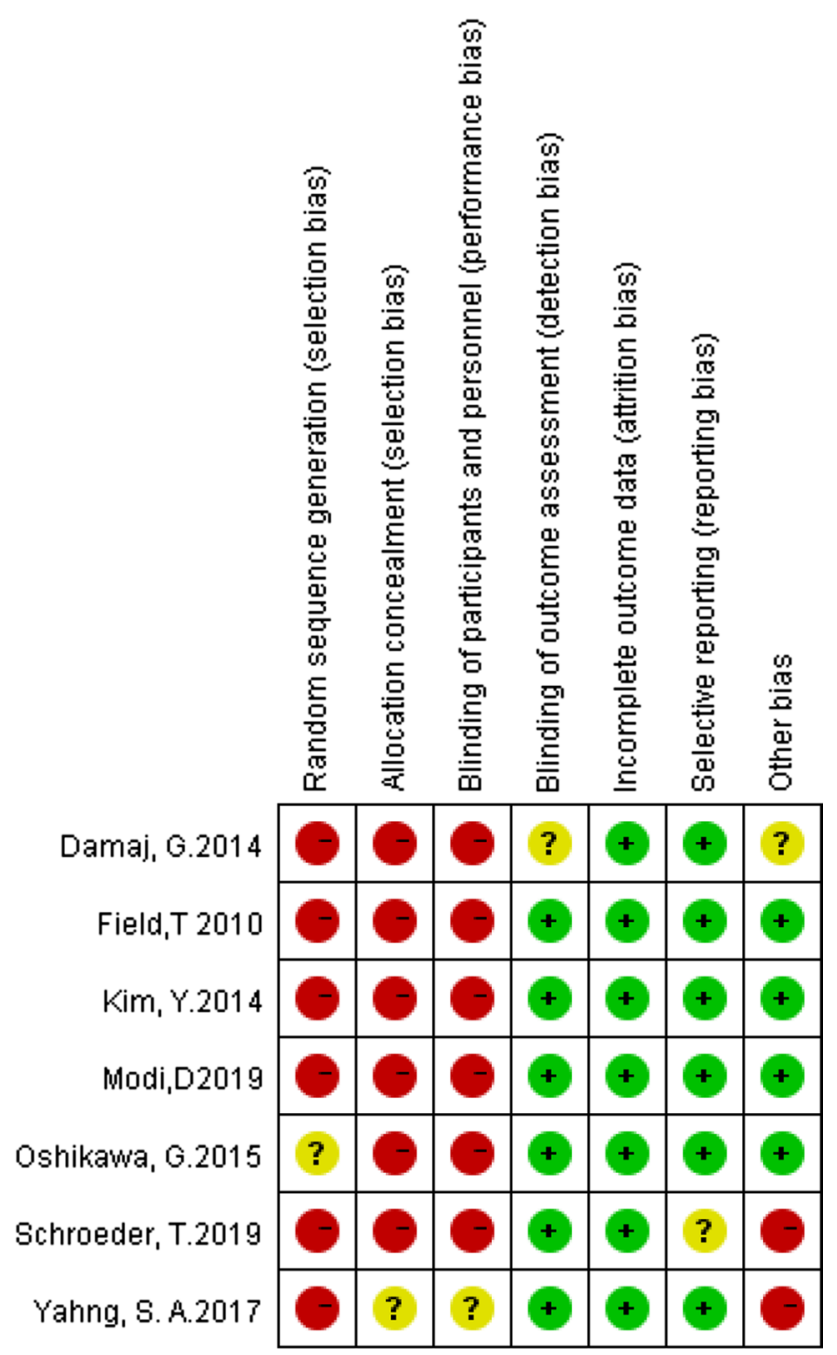

Fig. 2 Summary of research bias risk

were excluded from irrelevant subjects or research types. A total of 35 studies were to be reviewed. Among them, the excluded studies were used as meeting summaries, and 28 were excluded. Because of insufficient data or irrelevant results, the final 7 studies were included in the meta-analysis[21-27].

\section{Clinical characteristics of patients}

All these seven studies were retrospective. The total number of patients was 820, of which 395 received HMAs before allo-HSCT, and the control group received BSC. The basic principle of treatment decision was not clearly stated in most articles. The decision was based on clinical conditions and doctors' judgment. However, according to the comparison of patients' characteristics in seven studies, two of them showed that the median age of HMAs group was higher than that of the control group, and patients who chose the BSC for bridging treatment were more inclined to early transplantation.

\section{Analysis of outcomes}

As shown in Fig. 4 (HR and 95\% CI forest plots to assess OS with HMAs before allo-HSCT), all cohort studies compared the effectiveness of HMAs before allo-HSCT in MDS patients. Our results showed that administration of HMAs as pre-transplantation treatment did not improve OS (HR $=0.86,95 \%$ CI: 0.64-1.15, $p=0.32)$, while the heterogeneity of the study was low $\left(\mathrm{I}^{\wedge} 2=0 \%, p=0.86\right)$.

\section{Discussion}

In this study, we systematically analyzed all clinical studies in which HMAs were applied prior to allo-HSCT. It showed that MDS patients did not benefit from HMAs when subsequently underwent allo-HSCT. There was no significant improvement in OS after HS.

Although new drugs are constantly evolving, alloHSCT remains the only treatment for cure which leads to complete and permanent eradication of the MDS aberrant clone, as evidenced by long-term hematopoiesis. 
Fig. 3 Study selection flowchart
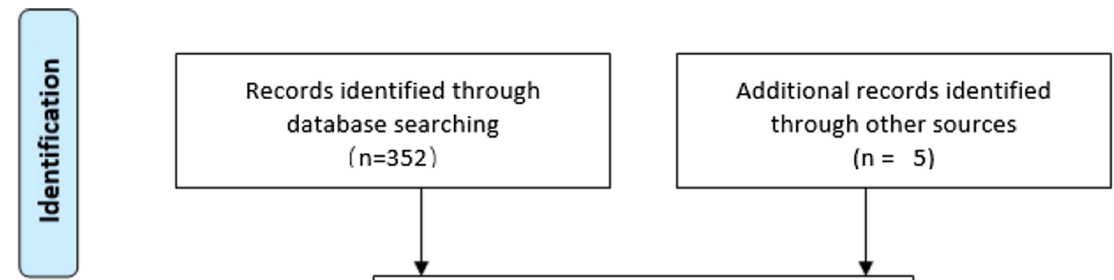

$$
(n=352)
$$

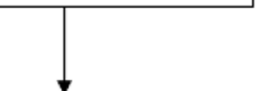

Records after duplicates removed $(n=289)$
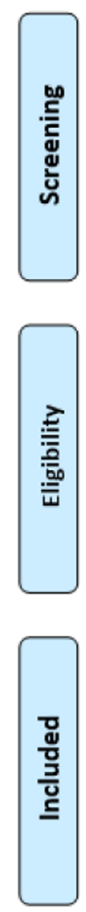

Studies included in
qualitative synthesis $(n=7)$

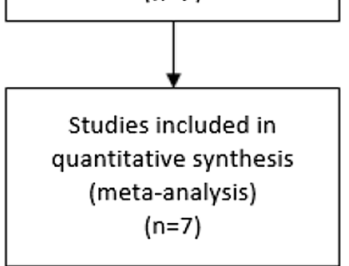

Experimental

Control

Odds Ratio

Study or Subgroup

Events Total

ents Tot

Schroeder, T.2019

Field,T 2010

Oshikawa, G.2015

Modi,D2019

Damaj, G.2014

Yahng, S. A.2017

Kim, Y.2014

$15 \quad 34$

$14 \quad 30$

$11 \quad 15$

$47 \quad 80$

$0.86[0.64,1.15]$

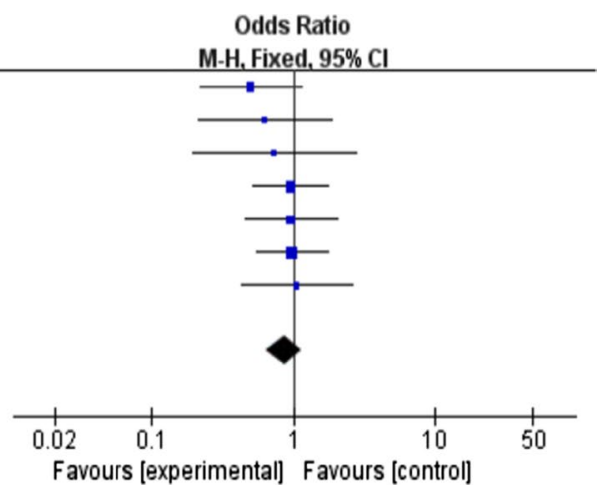

Fig. 4 Forest plots

Cytoreductive therapy prior to allo-HSCT is advised for patients who have $\geq 10 \%$ bone marrow myeloblasts [10]. While patients aged from 60 to 75 years old account for the majority of MDS patients. Primary endpoints for treatment of elderly MDS patients were maintaining a good quality of life rather than curative. Although MDS cannot be cured by HMAs, the emergence of hypomethylation treatment makes patients get better response, which is proved by stable blood count, transfusion independence and acceptable safety[6, 28-30]. In this sense, hypomethylation treatment is helpful for allo-HSCT, because it can obtain incalculable pre-transplant preparation time (donor seeking, financial support, etc.). TP53 mutations and complex karyotypes are more common in elderly patients. Some studies have shown that MDS/AML patients with TP53 mutations and/ or complex karyotypes have good initial 
response rates to decitabine [31-33]. It was also reported that AZA improved OS and relapse free survival (RFS) for higher-risk myelodysplastic syndrome (HR-MDS) patients with chromosome 7 abnormalities [34,35]. This suggests that HMAs therapy before allo-HSCT may be effective in MDS patients with complex karyotype and/or TP53 mutations.

The adverse effect of HMAs cannot be ignored. Potential myelosuppression may increase the chance of infection and bleeding events, even life-threatening. All interventions aimed at reducing disease burden before allo-HSCT were likely to increase the risk of complications and inability to receive transplantation [36]. In these seven studies, many patients failed to accept allo-HSCT due to disease progression or treatment-related death.

Yahng et al. reported that, through pre-HSCT hypomethylating treatment (HMT), achieving bone marrow complete response (mCR) was significantly associated with superior 4-year disease-free survival (DFS) compared to no marrow response group $(87.3 \%$ vs $10.7 \%$, $p<0.001)$. This difference was also evident in OS $(90.9 \%$ vs $8.6 \%, p<0.001)$, cumulative incidences of relapse (CIR) $(6.5 \%$ vs $45.4 \%, p<0.001)$ and treatment-related mortality (TRM) $(6.2 \%$ vs $43.9 \%, p<0.001)$ [37]. Another study showed that the DFS of patients accepted HMAs as bridging treatment was slightly higher than that of the BSC group (71.2\% vs 59.2\%). It also compared AZA responders who reached $\mathrm{CR}, \mathrm{mCR}$, or $\mathrm{SD}$ with $\mathrm{HI}$ with non-responders, better OS (100\% vs $66.7 \%, p=0.066)$ and DFS (75\% vs $50 \%, p=0.305$ ) were observed [26]. Voso et al. also found that AZA treatment before transplantation was beneficial if patients reached CR[38]. While no significant difference was found between pre-SCT AZA responders and non-responders in OS and RFS in another research [23]. There were also researches claimed that pretransplantation therapy may favor the selection of resistant clones. Patients given the BSC had a higher likelihood to respond to HMAs as salvage therapy for relapse in comparison with patients undergoing bridging therapy[24]. The effect of HMAs on disease progression or relapse after transplantation was not significant in three articles. The CIR was comparable between the HMT group and the BSC group $(6.2 \%$ vs $0 \%, 35 \%$ vs $36 \%, 31 \%$ vs $36 \%)$ [21-23]. Three studies reported the RFS of HMAs group was not better than that of BSC group (38\% vs 38\%, 37\% vs $42 \%, 41 \%$ vs $51 \%$ ) [22-24]. Similarly, Modi et al. concluded that no association was found between reduced post-transplant relapse and improved survival with the use of HMAs for cytoreductive therapy before allo-HSCT [27]. Interestingly, patients who received BSC performed as well as patients with blast counts $<5 \%$ and received HMAs. The patients who achieved cytoreduction with blasts counts $<5 \%$ fared better than $\geq 5 \%$ blast, which implies chemosensitivity and the biology of the disease affect the post-HSCT outcome, rather than the pre-transplantation treatment. Previous studies have also reported similar results $[39,40]$.

Besides, some pre-clinical studies have shown the anti-graft-versus-host disease (anti-GVHD) effects of AZA[41-43]. Among current retrospective clinical analysis, three studies showed that the use of pre-HSCT HMAs did not reduce the incidence of GVHD [21, 23, 26]. The timing of transplantation also plays a key role in the treatment and prognosis of MDS patients. For low and intermediate-1 risk MDS, delayed allo-HSCT is associated with maximum life expectancy, while for intermediate- 2 and high-risk MDS, direct transplantation can obtain the maximum survival time [44]. This requires doctors to make decisions based on experience and family consultation.

Our research has a few limitations. First of all, different studies used different analytical models, which may explain the heterogeneity of seven studies. Second, the number of participants in eligible studies was too small to conduct subgroup analyses. In addition, there were many clinical heterogeneity in the study, such as the type of HMAs, the treatment of the control group, the age and gender, MDS subtypes, HLA differences, conditioning regime and follow-up time differences, any of these may affect the clinical results. In conclusion, our meta-analysis showed that HMAs as a bridging therapy before allo-HSCT did not improve the long-term survival. However, due to the limitations of the original studies, our conclusions need to be further verified by a larger sample and randomized controlled design prospective study. This will be instructive for the treatment of MDS patients.

Author contributions LL put forward the idea of the article, and MJ carried out literature retrieval and data analysis. The first draft of the manuscript was written by MJ, LL strictly revised the work, and all the authors made comments on the manuscript. All the authors read and approved the final manuscript.

Funding The study is supported by the Youth Science Foundation of National Natural Science Foundation of China (Grant No.81600097). The funding was used for data acquisition and maintenance.

\section{Declarations}

Conflict of interest The authors have no conflicts of interest to declare that are relevant to the content of this article.

Ethics approval We performed the meta-analysis according to the guidelines of the Cochrane Handbook for Systematic Reviews of Interventions. The Research Ethics Committee of the First Affiliated Hospital of Zhengzhou University has confirmed that no ethical approval was required.

Informed consent It is not necessary to obtain consent because of the already available data. 
Open Access This article is licensed under a Creative Commons Attribution 4.0 International License, which permits use, sharing, adaptation, distribution and reproduction in any medium or format, as long as you give appropriate credit to the original author(s) and the source, provide a link to the Creative Commons licence, and indicate if changes were made. The images or other third party material in this article are included in the article's Creative Commons licence, unless indicated otherwise in a credit line to the material. If material is not included in the article's Creative Commons licence and your intended use is not permitted by statutory regulation or exceeds the permitted use, you will need to obtain permission directly from the copyright holder. To view a copy of this licence, visit http://creativecommons.org/licenses/by/4.0/.

\section{References}

1. Hosono N. Genetic abnormalities and pathophysiology of MDS. Int J Clin Oncol. 2019;24(8):885-92. https://doi.org/10.1007/ s10147-019-01462-6.

2. Shallis RM, Ahmad R, Zeidan AM. The genetic and molecular pathogenesis of myelodysplastic syndromes. Eur J Haematol. 2018;101(3):260-71. https://doi.org/10.1111/ejh.13092.

3. Zahid MF, Patnaik MM, Gangat N, Hashmi SK, Rizzieri DA. Insight into the molecular pathophysiology of myelodysplastic syndromes: targets for novel therapy. Eur J Haematol. 2016;97(4):313-20. https://doi.org/10.1111/ejh.12771.

4. Baek DW, Lee YJ, Kim H, Ahn SY, Ahn JS, Shin HJ, et al. Response to hypomethylating agents improves long-term outcomes for lower-risk patients with myelodysplastic syndrome in case-matched cohorts. Ann Hematol. 2018;97(12):2309-17. https://doi.org/10.1007/s00277-018-3458-7.

5. Fenaux P, Mufti GJ, Hellstrom-Lindberg E, Santini V, Finelli C, Giagounidis A, et al. Efficacy of azacitidine compared with that of conventional care regimens in the treatment of higher-risk myelodysplastic syndromes: a randomised, open-label, phase III study. Lancet Oncol. 2009;10(3):223-32. https://doi.org/10. 1016/S1470-2045(09)70003-8.

6. Lubbert M, Suciu S, Baila L, Ruter BH, Platzbecker U, Giagounidis $\mathrm{A}$, et al. Low-dose decitabine versus best supportive care in elderly patients with intermediate- or high-risk myelodysplastic syndrome (MDS) ineligible for intensive chemotherapy: final results of the randomized phase III study of the European Organisation for Research and Treatment of Cancer Leukemia Group and the German MDS Study Group. J Clin Oncol. 2011;29(15):1987-96. https://doi.org/10.1200/JCO.2010.30. 9245.

7. Komrokji RS. Treatment of higher-risk myelodysplastic syndromes after failure of hypomethylating agents. Clin Lymphoma Myeloma Leuk. 2015;15(Suppl):S56-9. https://doi.org/10. 1016/j.clml.2015.03.010.

8. Roberts DA, Steensma DP. Outlook and management of patients with myelodysplastic syndromes failed by hypomethylating agents. Curr Hematol Malig Rep. 2015;10(3):318-28. https:// doi.org/10.1007/s11899-015-0273-2.

9. Zeidan AM, Kharfan-Dabaja MA, Komrokji RS. Beyond hypomethylating agents failure in patients with myelodysplastic syndromes. Curr Opin Hematol. 2014;21(2):123-30. https://doi. org/10.1097/MOH.0000000000000016.

10. de Witte T, Bowen D, Robin M, Malcovati L, Niederwieser D, Yakoub-Agha I, et al. Allogeneic hematopoietic stem cell transplantation for MDS and CMML: recommendations from an international expert panel. Blood. 2017;129(13):1753-62. https://doi.org/10.1182/blood-2016-06-724500.

11. de Witte T, Hermans J, Vossen J, Bacigalupo A, Meloni G, Jacobsen $\mathrm{N}$, et al. Haematopoietic stem cell transplantation for patients with myelo-dysplastic syndromes and secondary acute myeloid leukaemias: a report on behalf of the Chronic Leukaemia Working Party of the European Group for Blood and Marrow Transplantation (EBMT). Br J Haematol. 2000;110(3):620 30. https://doi.org/10.1046/j.1365-2141.2000.02200.x.

12. Kindwall-Keller T, Isola LM. The evolution of hematopoietic SCT in myelodysplastic syndrome. Bone Marrow Transpl. 2009;43(8):597-609. https://doi.org/10.1038/bmt.2009.28.

13. Scott BL, Sandmaier BM, Storer B, Maris MB, Sorror ML, Maloney DG, et al. Myeloablative vs nonmyeloablative allogeneic transplantation for patients with myelodysplastic syndrome or acute myelogenous leukemia with multilineage dysplasia: a retrospective analysis. Leukemia. 2006;20(1):128-35. https:// doi.org/10.1038/sj.leu.2404010.

14. De Padua SL, de Lima M, Kantarjian H, Faderl S, Kebriaei P, Giralt S, et al. Feasibility of allo-SCT after hypomethylating therapy with decitabine for myelodysplastic syndrome. Bone Marrow Transpl. 2009;43(11):839-43. https://doi.org/10.1038/bmt.2008. 400.

15. Festuccia M, Baker K, Gooley TA, Sandmaier BM, Deeg HJ, Scott BL. Hematopoietic cell transplantation in myelodysplastic syndromes after treatment with hypomethylating agents. Biol Blood Marrow Transpl. 2017;23(9):1509-14. https://doi.org/10.1016/j. bbmt.2017.05.034.

16. Liu ZX, Lyu MN, Wang QQ, Zhai WH, Pang AM, Ma QL, et al. Outcomes and prognostic factors of myelodysplastic syndrome patients with allogeneic hematopoietic stem cell transplantation. Zhonghua Xue Ye Xue Za Zhi. 2019;40(6):484-9. https://doi.org/ 10.3760/cma.j.issn.0253-2727.2019.06.007.

17. Bertz MLH, Ruter B, Marks R, Claus R, Wasch R, et al. Nonintensive treatment with low-dose 5-aza-2'-deoxycytidine (DAC) prior to allogeneic blood SCT of older MDS/AML patients. Bone Marrow Transpl. 2009;44(9):585-8. https://doi.org/10.1038/bmt. 2009.64

18. Zhou J, Depei W, Fu C, Sun A, Qiu H, Jin Z et al. Decitabine as induction therapy for median-to-high-risk myelodysplastic syndromes(MDS) and acute myeloid leukemia(AML) before allogeneic stem cell transplantation. Blood. 2013;122(21).

19. Pinto A, Zagonel V. 5-Aza-2'-deoxycytidine (Decitabine) and 5-azacytidine in the treatment of acute myeloid leukemias and myelodysplastic syndromes: past, present and future trends. Leukemia. 1993;7(Suppl 1):51-60.

20. Pinto A, Zagonel V, Attadia V, Bullian PL, Gattei V, Carbone A, et al. 5-Aza-2'-deoxycytidine as a differentiation inducer in acute myeloid leukaemias and myelodysplastic syndromes of the elderly. Bone Marrow Transplant. 1989;4(Suppl 3):28-32.

21. Yahng SA, Kim M, Kim TM, Jeon YW, Yoon JH, Shin SH, et al. Better transplant outcome with pre-transplant marrow response after hypomethylating treatment in higher-risk MDS with excess blasts. Oncotarget. 2017;8(7):12342-54. https://doi.org/10.18632/ oncotarget.12511.

22. Schroeder T, Wegener N, Lauseker M, Rautenberg C, Nachtkamp $\mathrm{K}$, Schuler E, et al. Comparison between upfront transplantation and different pretransplant cytoreductive treatment approaches in patients with high-risk myelodysplastic syndrome and secondary acute myelogenous leukemia. Biol Blood Marrow Transpl. 2019;25(8):1550-9. https://doi.org/10.1016/j.bbmt.2019.03.011.

23. Oshikawa G, Yoshioka K, Takahashi Y, Shingai N, Ikegawa S, Kobayashil $\mathrm{T}$, et al. Impact of prior azacitidine on the outcome of allogeneic hematopoietic transplantation for myelodysplastic syndrome. Pathol Oncol Res. 2015;21(4):1037-43. https://doi.org/ 10.1007/s12253-015-9933-8.

24. Kim Y, Kim IH, Kim HJ, Park S, Lee KH, Kim SJ, et al. Multicenter study evaluating the impact of hypomethylating agents as bridging therapy to hematopoietic stem cell transplantation in 
myelodysplastic syndromes. Int J Hematol. 2014;99(5):635-43. https://doi.org/10.1007/s12185-014-1549-3.

25. Field T, Perkins J, Huang Y, Kharfan-Dabaja MA, Alsina M, Ayala E, et al. 5-Azacitidine for myelodysplasia before allogeneic hematopoietic cell transplantation. Bone Marrow Transpl. 2010;45(2):255-60. https://doi.org/10.1038/bmt.2009.134.

26. Damaj G, Mohty M, Robin M, Michallet M, Chevallier P, Beguin $\mathrm{Y}$, et al. Upfront allogeneic stem cell transplantation after reducedintensity/nonmyeloablative conditioning for patients with myelodysplastic syndrome: a study by the Societe Francaise de Greffe de Moelle et de Therapie Cellulaire. Biol Blood Marrow Transplant. 2014;20(9):1349-55. https://doi.org/10.1016/j.bbmt.2014.05.010.

27. Modi D, Kim S, Singh V, Ayash L, Alavi A, Ratanatharathorn $\mathrm{V}$, et al. Pre-transplant hypomethylating agents do not influence post-transplant survival in myelodysplastic syndrome. Leuk Lymphoma. 2019;60(11):2762-70. https://doi.org/10.1080/10428194. 2019.1605070.

28. Breccia M, Molica M, Zacheo I, Alimena G. Azacitidine for myelodysplastic patients aged $>65$ years: a review of clinical efficacy. Expert Opin Pharmacother. 2014;15(11):1621-30. https://doi.org/ 10.1517/14656566.2014.936849.

29. Kantarjian H, Issa JP, Rosenfeld CS, Bennett JM, Albitar M, DiPersio J, et al. Decitabine improves patient outcomes in myelodysplastic syndromes: results of a phase III randomized study. Cancer. 2006;106(8):1794-803. https://doi.org/10.1002/cncr.21792.

30. Silverman LR, Demakos EP, Peterson BL, Kornblith AB, Holland JC, Odchimar-Reissig R, et al. Randomized controlled trial of azacitidine in patients with the myelodysplastic syndrome: a study of the cancer and leukemia group B. J Clin Oncol. 2002;20(10):2429-40. https://doi.org/10.1200/JCO.2002.04.117.

31. Lubbert M, Ruter BH, Claus R, Schmoor C, Schmid M, Germing $\mathrm{U}$, et al. A multicenter phase II trial of decitabine as first-line treatment for older patients with acute myeloid leukemia judged unfit for induction chemotherapy. Haematologica. 2012;97(3):393-401. https://doi.org/10.3324/haematol.2011.048231.

32. Lubbert M, Suciu S, Hagemeijer A, Ruter B, Platzbecker U, Giagounidis A, et al. Decitabine improves progression-free survival in older high-risk MDS patients with multiple autosomal monosomies: results of a subgroup analysis of the randomized phase III study 06011 of the EORTC Leukemia Cooperative Group and German MDS Study Group. Ann Hematol. 2016;95(2):191-9. https://doi.org/10.1007/s00277-015-2547-0.

33. Welch JS, Petti AA, Miller CA, Fronick CC, O’Laughlin M, Fulton RS, et al. TP53 and decitabine in acute myeloid leukemia and myelodysplastic syndromes. N Engl J Med. 2016;375(21):202336. https://doi.org/10.1056/NEJMoa1605949.

34. Diez-Campelo M, Lorenzo JI, Itzykson R, Rojas SM, Berthon $\mathrm{C}$, Luno E, et al. Azacitidine improves outcome in higher-risk MDS patients with chromosome 7 abnormalities: a retrospective comparison of GESMD and GFM registries. Br J Haematol. 2018;181(3):350-9. https://doi.org/10.1111/bjh.15190.

35. Sanchez-Garcia J, Falantes J, Medina Perez A, HernandezMohedo F, Hermosin L, Torres-Sabariego A, et al. Prospective randomized trial of 5 days azacitidine versus supportive care in patients with lower-risk myelodysplastic syndromes without $5 \mathrm{q}$ deletion and transfusion-dependent anemia. Leuk Lymphoma.
2018;59(5):1095-104. https://doi.org/10.1080/10428194.2017. 1366998.

36. Gauthier J, Damaj G, Yakoub-Agha I. The role of pre-transplant debulking treatment in patients undergoing allogeneic stem cell transplantation for high-risk myelodysplastic syndrome. Bull Cancer. 2015;102(4):340-8. https://doi.org/10.1016/j.bulcan.2015.02. 009.

37. Yahng SA, Jeon YW, Yoon JH, Shin SH, Lee SE, Choi YS, et al. Dynamic prognostic value of the revised international prognostic scoring system following pretransplant hypomethylating treatment in myelodysplastic syndrome. Bone Marrow Transpl. 2017;52(4):522-31. https://doi.org/10.1038/bmt.2016.295.

38. Voso MT, Leone G, Piciocchi A, Fianchi L, Santarone S, Candoni A, et al. Feasibility of allogeneic stem-cell transplantation after azacitidine bridge in higher-risk myelodysplastic syndromes and low blast count acute myeloid leukemia: results of the BMT-AZA prospective study. Ann Oncol. 2017;28(7):1547-53. https://doi. org/10.1093/annonc/mdx154.

39. Damaj G, Duhamel A, Robin M, Beguin Y, Michallet M, Mohty $\mathrm{M}$, et al. Impact of azacitidine before allogeneic stem-cell transplantation for myelodysplastic syndromes: a study by the societe francaise de greffe de moelle et de therapie-cellulaire and the groupe-francophone des myelodysplasies. J Clin Oncol. 2012;30(36):4533-40. https://doi.org/10.1200/Jco.2012.44.3499.

40. Oran B, Kongtim P, Popat U, de Lima M, Jabbour E, Lu XY, et al. Cytogenetics, donor type, and use of hypomethylating agents in myelodysplastic syndrome with allogeneic stem cell transplantation. Biol Blood Marrow Transpl. 2014;20(10):1618-25. https:// doi.org/10.1016/j.bbmt.2014.06.022.

41. Choi J, Ritchey J, Prior JL, Holt M, Shannon WD, Deych E, et al. In vivo administration of hypomethylating agents mitigate graft-versus-host disease without sacrificing graft-versusleukemia. Blood. 2010;116(1):129-39. https://doi.org/10.1182/ blood-2009-12-257253.

42. Costantini B, Kordasti SY, Kulasekararaj AG, Jiang J, Seidl T, Abellan PP, et al. The effects of 5-azacytidine on the function and number of regulatory $\mathrm{T}$ cells and T-effectors in myelodysplastic syndrome. Haematologica. 2013;98(8):1196-205. https://doi.org/ 10.3324/haematol.2012.074823.

43. Sanchez-Abarca LI, Gutierrez-Cosio S, Santamaria C, CaballeroVelazquez T, Blanco B, Herrero-Sanchez C, et al. Immunomodulatory effect of 5-azacytidine $(5$-azaC): potential role in the transplantation setting. Blood. 2010;115(1):107-21. https://doi.org/10. 1182/blood-2009-03-210393.

44. Cutler CS, Lee SJ, Greenberg P, Deeg HJ, Perez WS, Anasetti $\mathrm{C}$, et al. A decision analysis of allogeneic bone marrow transplantation for the myelodysplastic syndromes: delayed transplantation for low-risk myelodysplasia is associated with improved outcome. Blood. 2004;104(2):579-85. https://doi.org/10.1182/ blood-2004-01-0338.

Publisher's Note Springer Nature remains neutral with regard to jurisdictional claims in published maps and institutional affiliations. 